\title{
PERANCANGAN SISTEM INFORMASI ADMINISTRASI PEMBINAAN K3 PADA PT. EXAUDI BINA KARYA
}

\author{
Ratna Purnama Sari ${ }^{1}$, Anus Wuryanto ${ }^{2}$ \\ Manajemen Informatika, Program Diploma III AMIK BSI Karawang, ratna@mail.com \\ Manajemen Informatika, Program Diploma III AMIK BSI Karawang, anus.awu@,bsi.ac.id
}

\begin{abstract}
At this time, where the development of technology and information developed very quickly. This has an impact on the ease in various fields of work, including the field of K3 faculty administration. The use of computer technology makes the process of OSH administration more effective and efficient. PT. Exaudi Bina Karya Karawang is a health and safety service company in the field of K3 training and training. It is one of the companies that still use manual system in its administrative process both in data recap and data storage process which still using physical document, so it is very possible to errors in recording and difficulties in searching data. Based on this background the authors are encouraged to create a program of $\mathrm{K} 3$ development guidance that is expected to help the process of $\mathrm{OSH}$ administration becomes more effective and efficient. K3 development guidance program is made by using software microsoft visual studio 2008 and microsoft access 2010 as database application. The use of OSH administration program to be the right solution to facilitate the process of input data coaching, input data company and input data participants. Easy in search of data and reports produced will be more accurate.
\end{abstract}

Keywords : Information System, information system design, K3 Development

\begin{abstract}
ABSTRAK
Pada masa sekarang ini, dimana perkembangan teknologi dan informasi berkembang dengan sangat cepat. Hal ini berdampak pada kemudahan dalam berbagai bidang pekerjaan, termasuk bidang administrasi pembinaan K3. Penggunaan teknologi komputer menjadikan proses administrasi K3 menjadi lebih efektif dan efisien. PT. Exaudi Bina Karya Karawang adalah perusahaan jasa keselamatan dan kesehatan kerja bidang pembinaan dan pelatihan K3. Merupakan salah satu perusahaan yang masih memakai sistem manual dalam proses administrasinya baik dalam proses rekap data serta penyimpanan data yang masih menggunakan dokumen fisik, sehingga sangat mungkin terjadinya kesalahan dalam pencatatan serta kesulitan dalam pencarian data. Berdasarkan latar belakang tersebut penulis terdorong untuk membuat program administrasi pembinaan K3 yang diharapkan dapat membantu proses administrasi K3 menjadi lebih efektif dan efisien. Program administrasi pembinaan K3 dibuat dengan menggunakan software microsoft visual studio 2008 dan microsoft access 2010 sebagai aplikasi basis datanya. Penggunaan program administrasi K3 menjadi solusi yang tepat untuk mempermudah proses input data pembinaan, input data perusahaan dan input data peserta. Mudah dalam pencarian data dan laporan yang dihasilkan akan lebih akurat.
\end{abstract}

Kata Kunci: Sistem Informasi, perancangan system informasi, Pembinaan K3 


\section{PENDAHULUAN}

Pada masa sekarang ini dimana semua kegiatan baik berupa rekap data atau pencatatan data maupun kegiatan yang lainnya sudah dilakukan dengan sistem yang sudah terkomputerisasi. Hal ini dimaksudkan agar dalam proses rekap data dapat dilakukan secara cepat dan tidak memakan waktu yang lama, selain itu sistem yang sudah terkomputerisasi akan lebih efektif dan efisien dibandingkan dengan sistem yang lama atau sistem manual. Beberapa software seperti visual basic, borland delphi, dan java biasa dipakai programer untuk merancang atau membuat sistem yang sudah terkomputerisasi yang nantinya akan memudahkan dalam pemakaian bagi penggunanya.

Nilai lebih dari sistem yang sudah terkomputerisasi dibandingkan dengan yang manual dalam proses rekap data diantaranya:

1. Dari segi input atau rekap data, penggunaan sistem yang sudah terkomputerisasi akan jauh lebih cepat bila dibandingkan dengan sistem manual atau yang masih menggunakan tulisan tangan maupun ketikan komputer secara manual.

2. Dari segi penyimpanan data, sistem yang sudah terkomputerisasi tidak lagi memerlukan banyak kertas maupun dokumen fisik untuk menyimpan data, karena semua data disimpan dalam file database yang mampu menampung banyak data.

3. Dari segi pencarian data, sistem yang sudah terkomputerisasi akan lebih mudah dalam pencarian data, karena sudah dirancang sedemikian rupa untuk memudahkan dalam pencarian data. Sehingga tidak perlu lagi melihat dokumen satu persatu yang akan memakan banyak waktu.

4. Dari segi tenaga kerja, penggunaan sistem yang sudah terkomputerisasi tidak lagi memerlukan banyak tenaga kerja sehingga perusahaan dapat melakukan efisiensi dalam penggunaan biaya tenaga kerja.

Dalam kehidupan masyarakat Indonesia saat ini, penggunaan sistem yang sudah terkomputerisasi biasanya hanya dapat ditemukan pada perusahaan-perusahaan yang besar. Dan masih jarang instansi atau perusahaan kecil dan menengah yang menggunakan sistem yang sudah terkomputerisasi, hal ini dikarenakan mahalnya sistem yang sudah terkomputerisasi tersebut. Untuk membantu keterbatasan ini maka akan lebih baik jika dibuatkan sebuah sistem yang sudah terkomputerisasi yang khusus didedikasikan kepada instansi atau perusahaan kecil dan menengah untuk kemajuan pada masa yang akan datang. PT. Exaudi Bina Karya Karawang adalah salah satu perusahaan yang masih memakai sistem manual dalam proses rekap datanya. Berdasarkan latar belakang diatas, penulis terdorong untuk membuat sistem atau program yang sudah terkomputerisasi. Namun karena ruang lingkupnya yang terlalu besar, penulis hanya merancang sistem atau program administrasi pembinaan K3 yang dikhususkan untuk PT. Exaudi Bina Karya Karawang, sehingga penulis mengambil judul untuk Penelitian ini adalah " Perancangan Program Administrasi Pembinaan K3 pada PT. Exaudi Bina Karya ".

\section{LANDASAN TEORI}

\subsection{Konsep Dasar Program}

Sebelum lebih dalam mengupas Penelitian, alangkah baiknya apabila diketahui terlebih dahulu definisi serta uraian singkat mengenai konsep dasar dari program yang berhubungan dengan penelitian.

\subsection{Program}

Menurut Sutarman (2009:3) dalam bukunya pengantar teknologi informasi mengemukakan bahwa "program adalah barisan perintah atau instruksi yang disusun sehingga dapat dipahami oleh komputer dan kemudian dijalankan sebagai barisan perhitungan numerik, dimana barisan perintah tersebut berhingga, berakhir, dan menghasilkan output'. 
Beberapa langkah yang harus diperhatikan oleh pemrogram sebelum mengimplementasikan suatu permasalahan dalam program menurut Kristanto (2009:4) adalah:

1. Mendefinisikan masalah

2. Mencari solusi untuk masalah

3. Memilih teknik pemecahan masalah dan algoritma

4. Menulis program

5. Melakukan testing dan debuging

6. Melakukan dokumentasi

7. Melakukan pemeliharaan

\subsection{Basis Data}

Junindar (2008:19) mendefinisikan bahwa "Database (basis data) merupakan kumpulan data yang saling berhubungan satu sama dengan lainnya yang tersimpan di perangkat keras komputer dan diperlukan suatu perangkat lunak untuk memanipulasi basis data tersebut".

Sedangkan Sistem basis data atau database management sistem (DBMS) menurut Junindar (2008:19) adalah "Perangkat lunak yang digunakan untuk mengendalikan data, termasuk penyimpanan data, pengambilan data, keamanan data, dan integritas data".

\subsection{Model Pengembangan Software}

Menurut Rosa dan Shalahuddin (2015:28), "Model waterfall adalah model SDLC yang paling sederhana, model ini hanya cocok untuk pengembangan perangkat lunak dengan spesifikasi yang tidak berubah-ubah". Model SDLC air terjun (waterfall) sering juga disebut model sekuensial linier (sequential linear) atau alur hidup klasik (classic life cycle). Berikut ini adalah tahapan model air terjun:

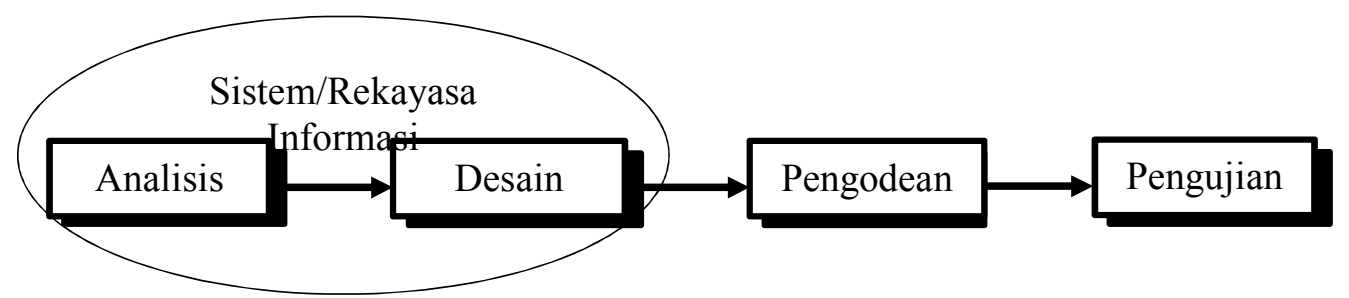

Sumber: Rosa dan Shalahuddin (2015:29)

Gambar 1. Model Waterfall

\subsubsection{Analisis kebutuhan perangkat lunak}

Proses pengumpulan kebutuhan dilakukan secara intensif untuk mespesifikasikan kebutuhan perangkat lunak agar dapat dipahami perangkat lunak seperti apa yang dibutuhkan oleh user. Spesifikasi kebutuhan perangkat lunak pada tahap ini perlu untuk didokumentasikan.

\subsubsection{Desain}

Desain perangkat lunak adalah proses multi langkah yang fokus pada desain pembuatan program perangkat lunak termasuk struktur data, arsitektur perangkat lunak, representasi antarmuka, dan prosedur pengkodean. Tahap ini mentranslasi kebutuhan perangkat lunak dari tahap analisis kebutuhan ke representasi desain agar dapat diimplementasikan menjadi program pada tahap selanjutnya.

\subsubsection{Pembuatan kode program}

Desain harus ditranslasikan ke dalam program perangkat lunak. Hasil dari tahap ini adalah program komputer sesuai dengan desain yang telah dibuat pada tahap desain.

\subsubsection{Pengujian (Testing)}

Pengujiian fokus pada perangkat lunak secara dari segi lojik dan fungsional dan memastikan bahwa semua bagian sudah diuji. Hal ini dilakukan untuk meminimalisir 
kesalahan (error) dan memastikan keluaran (output) yang dihasilkan sesuai dengan yang diinginkan.

\subsubsection{Pendukung (Support)}

Tidak menutup kemungkinan sebuah perangkat lunak mengalami perubahan ketika sudah dikirimkan ke user. Perubahan bisa terjadi karena adanya kesalahan yang muncul dan tidak terdeteksi saat pengujian atau perangkat lunak harus beradaptasi dengan lingkungan baru. Tahap pendukung atau pemeliharaan dapat mengulangi proses pengembangan mulai dari analisis spesifikasi untuk perubahan perangkat lunak yang sudah ada, tapi tidak untuk membuat perangkat lunak baru.

\section{METODE PENELITIAN}

\subsection{Lokasi Penelitian}

Tempat atau lokasi PT. Exaudi Bina Karya berlokasi di Resinda Complex Ruko Race TA 05 No 30 Karawang. Merupakan salah satu perusahaan jasa keselamatan dan kesehatan kerja (PJK3) bidang pembinaan dan pelatihan K3, yang ditunjuk Direktorat Jenderal Pembinaan dan Pengawasan Ketenagakerjaan Departemen Tenaga Kerja dan Transmigrasi RI

\subsection{Teknik Pengumpulan Data dan Analisa Data}

Dalam pengumpulan data dan informasi yang diperlukan untuk penelitian ini, penulis mengadakan penelitian dengan menggunakan beberapa metode antara lain:

\subsubsection{Metode Observasi (Observation)}

Kegiatan ini dimaksudkan untuk secara langsung melakukan pengamatan dan peninjauan, yang dilakukan oleh peneliti pada PT. Exaudi Bina Karya Karawang sehingga memperoleh informasi yang jelas berkaitan dengan kegiatan yang dilakukan pada PT. Exaudi Bina Karya Karawang.

\subsubsection{Metode Wawancara (Interview)}

Metode ini adalah pengumpulan data melalui tanya jawab yang dilakukan peneliti kepada Direktur serta bagian Administrasi PT. Exaudi Bina Karya Karawang secara langsung.

\subsubsection{Metode Studi Pustaka (Library Research)}

Metode studi pustaka digunakan peneliti agar mendapatkan sumber referensi yang baik berupa buku maupun artikel di internet untuk memperoleh bahan tentang perancangan program yang baik yang berhubungan dengan penelitian yang penulis buat.

\section{PEMBAHASAN}

\subsection{Analisis Kebutuhan}

Mengindentifikasi kebutuhan fungsional program, baik pengguna maupun sistem disertai dengan permodelan use case diagram dan deskripsi skenario use case yang terkait dengan proses administrasi pembinaan K3 pada PT. Exaudi Bina Karya Karawang.

\subsection{Identifikasi Kebutuhan}

Identifikasi kebutuhan pengguna maupun sistem yang terkait dengan proses administrasi pembinaan K3 pada PT. Exaudi Bina Karya Karawang

\subsection{Kebutuhan Pengguna}

Dalam program Administrasi pembinaan K3 terdapat dua pengguna yang dapat saling berinteraksi dalam lingkungan sistem, yaitu: Bagian Administrasi atau User dan Bagian Administrator atau Admin. Kedua pengguna tersebut memiliki karakteristik interaksi dengan sistem yang berbeda-beda dan memiliki kebutuhan informasi yang berbeda-beda, seperti berikut:

\section{Skenario kebutuhan bagian Administrator atau Admin}

a. Login program

b. Backup database 
c. Mengelola data user

d. Mengganti password sendiri

\section{Skenario kebutuhan bagian $A d m i n i s t r a s i$ atau $U$ ser}

a. Login program

b. Mengelola data perusahaan, data peserta dan data pembinaan

c. Mengelola input data pembinaan

d. Mencetak atau print data perusahaan, data peserta, data pembinaan dan laporan pembinaan

e. Mengganti password sendiri

\subsection{Kebutuhan Sistem}

1. Pengguna harus melakukan login terlebih dahulu untuk dapat pengakses program ini dengan memasukkan iduser dan password

2. Sistem melakukan pengolahan dan menyimpan hasil data input

3. Sistem dapat menampilkan dan mencetak laporan

4. Pengguna harus melakukan logout setelah selesai menggunakan program

\subsection{Use Case Diagram}

Permodelan use case diagram dan deskripsi skenario use case yang terkait dengan proses administrasi pembinaan K3 pada PT. Exaudi Bina Karya Karawang. Permodelan use case diagram dapat digambarkan use case diagram dalam bentuk sea level untuk overview.

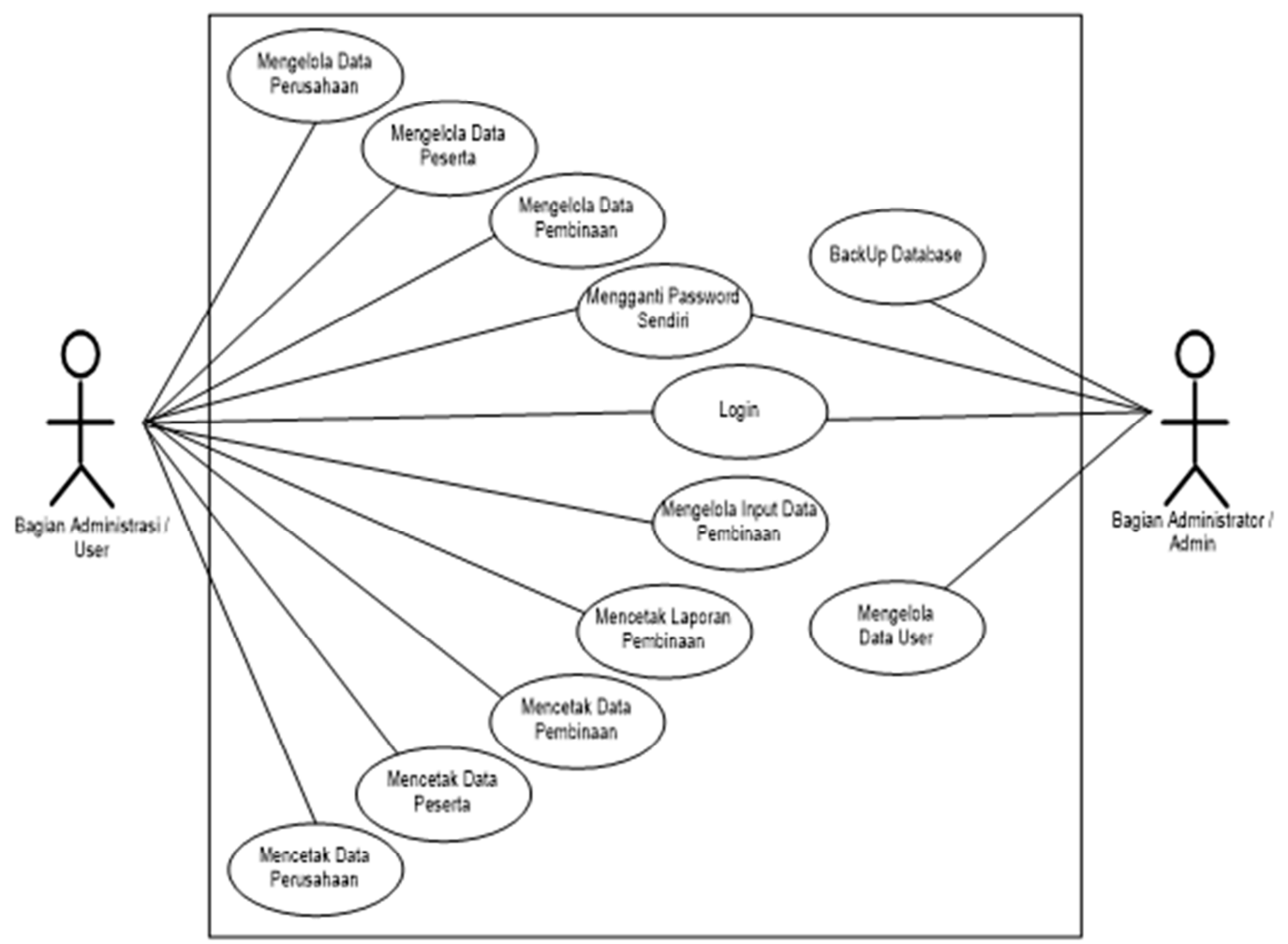

Gambar 2. Use Case Diagram Sistem Administrasi Pembinaan K3

\subsection{Sequence Diagram}

Rancangan arsitektur sequence diagram pada program administrasi pembinaan K3 pada PT. Exaudi Bina Karya Karawang. 


\subsubsection{Sequence Diagram Mengelola Data Perusahaan}

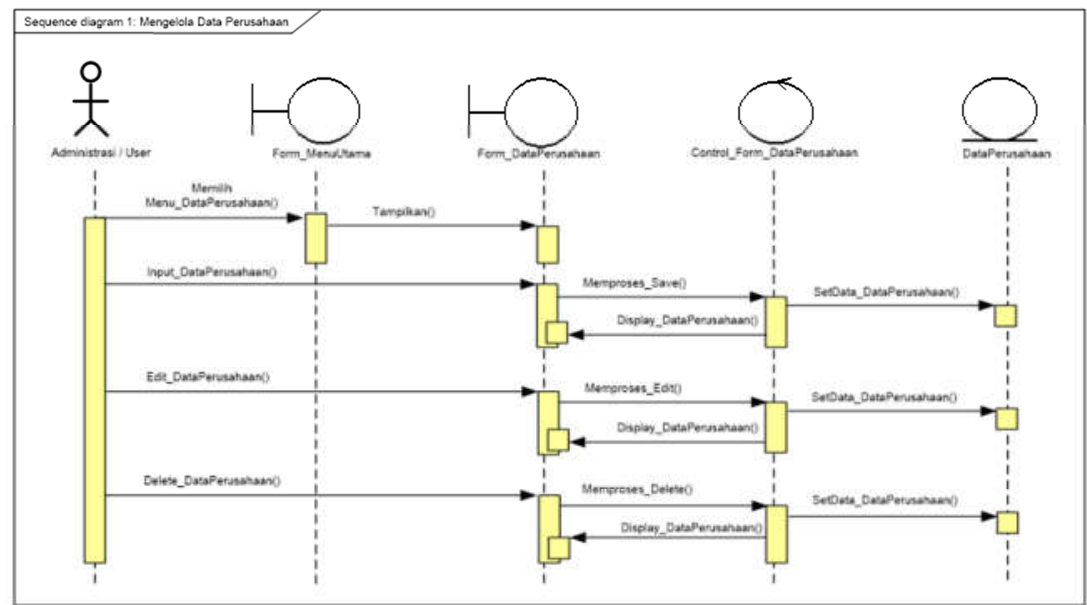

Gambar 3. Sequence Diagram Mengelola Data Perusahaan

\subsubsection{Sequence Diagram Mengelola Data Peserta}

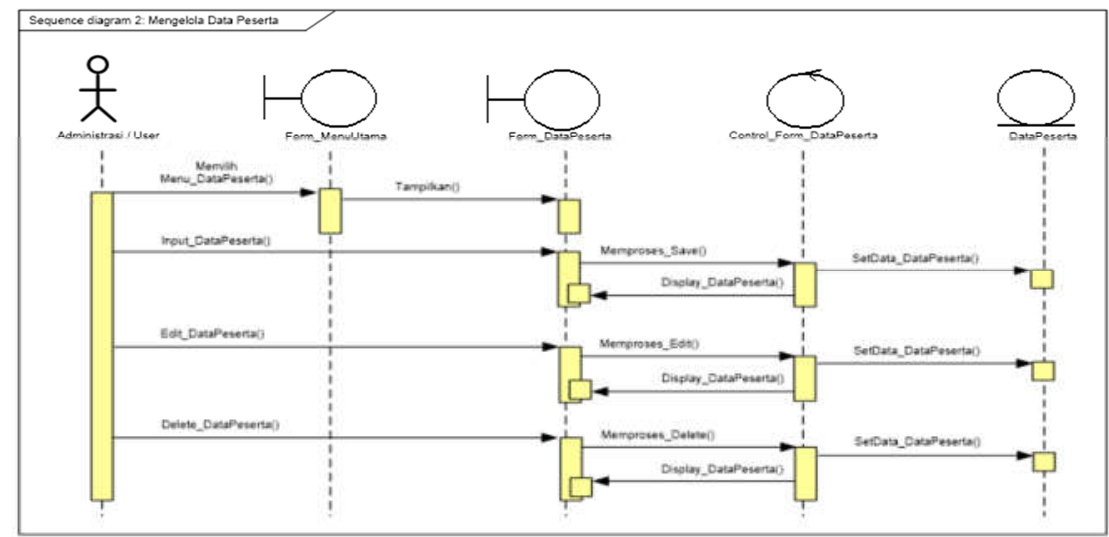

Gambar 4. Sequence Diagram Mengelola Data Peserta

\subsubsection{Sequence Diagram Login Program}

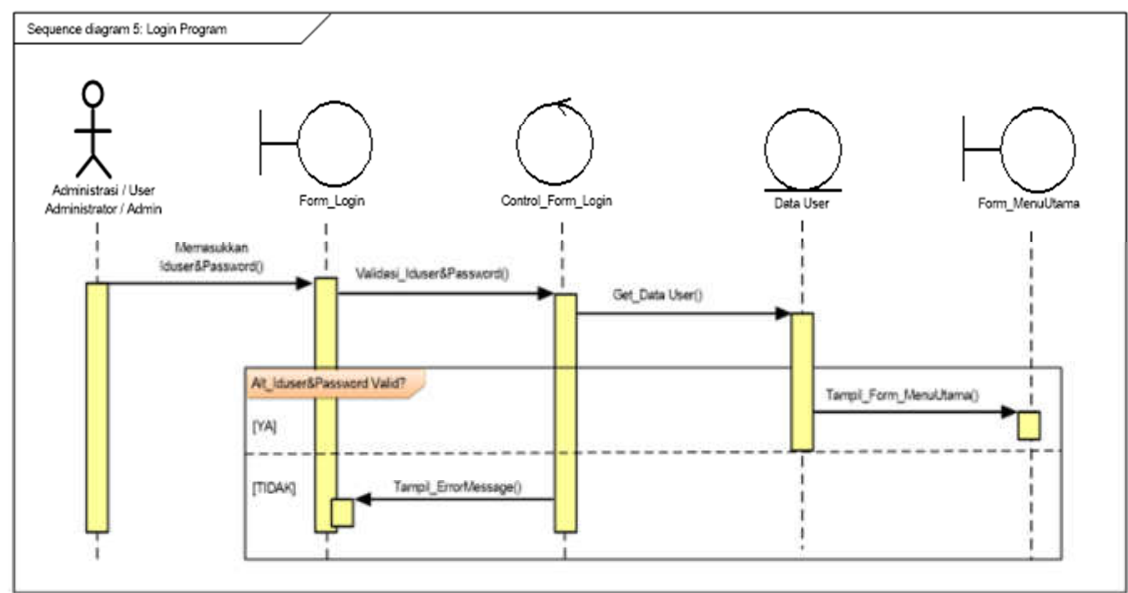

Gambar 5. Sequence Diagram Mengelola login program 


\subsubsection{Sequence Diagram Mencetak Data Pembinaan}

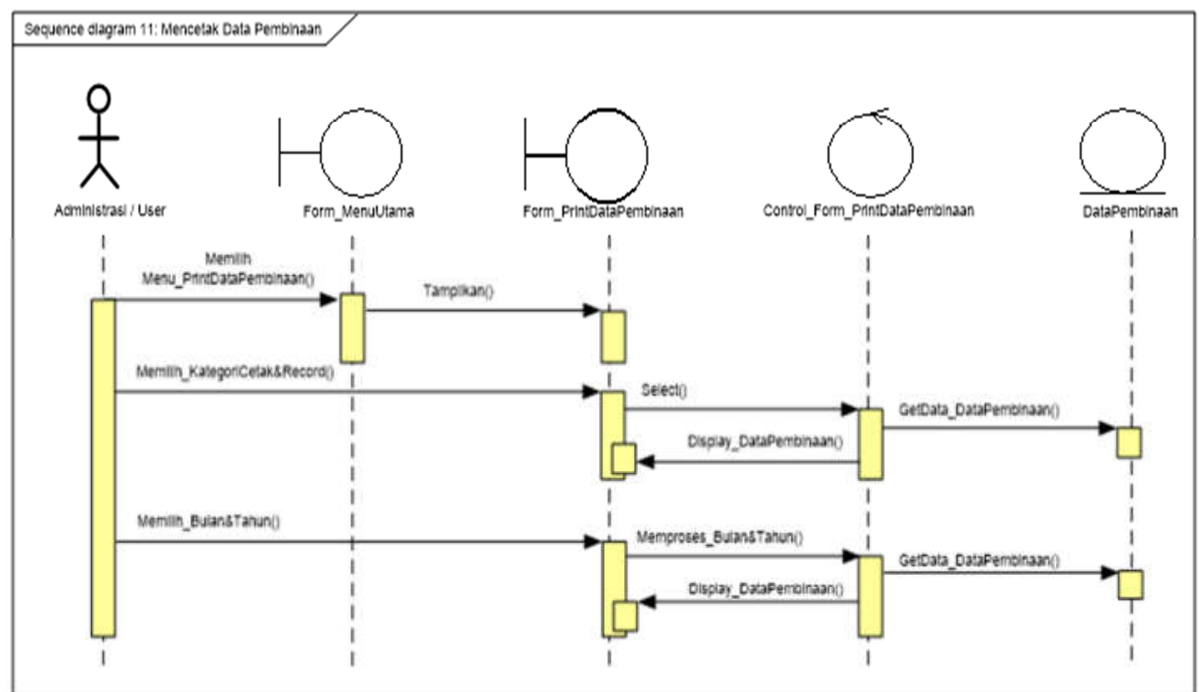

Gambar 6. Sequence Diagram Mengelola mencetak data pembinaan

\subsection{Rancangan Basis Data}

\subsubsection{Logical Record Structure}

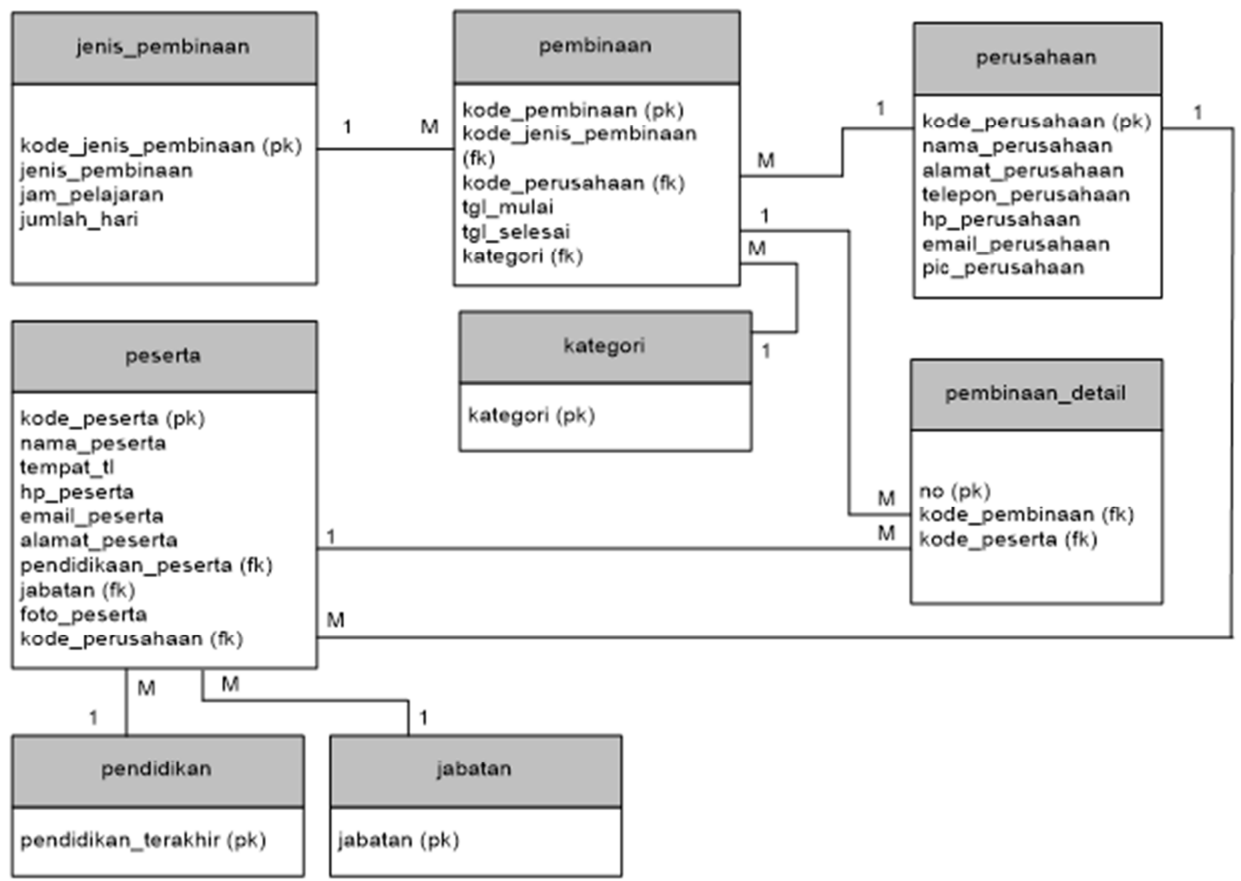

Gambar 7. Logical Record Struktur 
Jurnal Inkofar * Volume 1 No. 1, Juli 2018 * ISSN: 2615-3645 (Print) / 2581-2920 (Online)

Tersedia secara online di: http://www.politeknikmeta.ac.id/meta/ojs/

\subsubsection{Entity Relationship Diagram (ERD)}

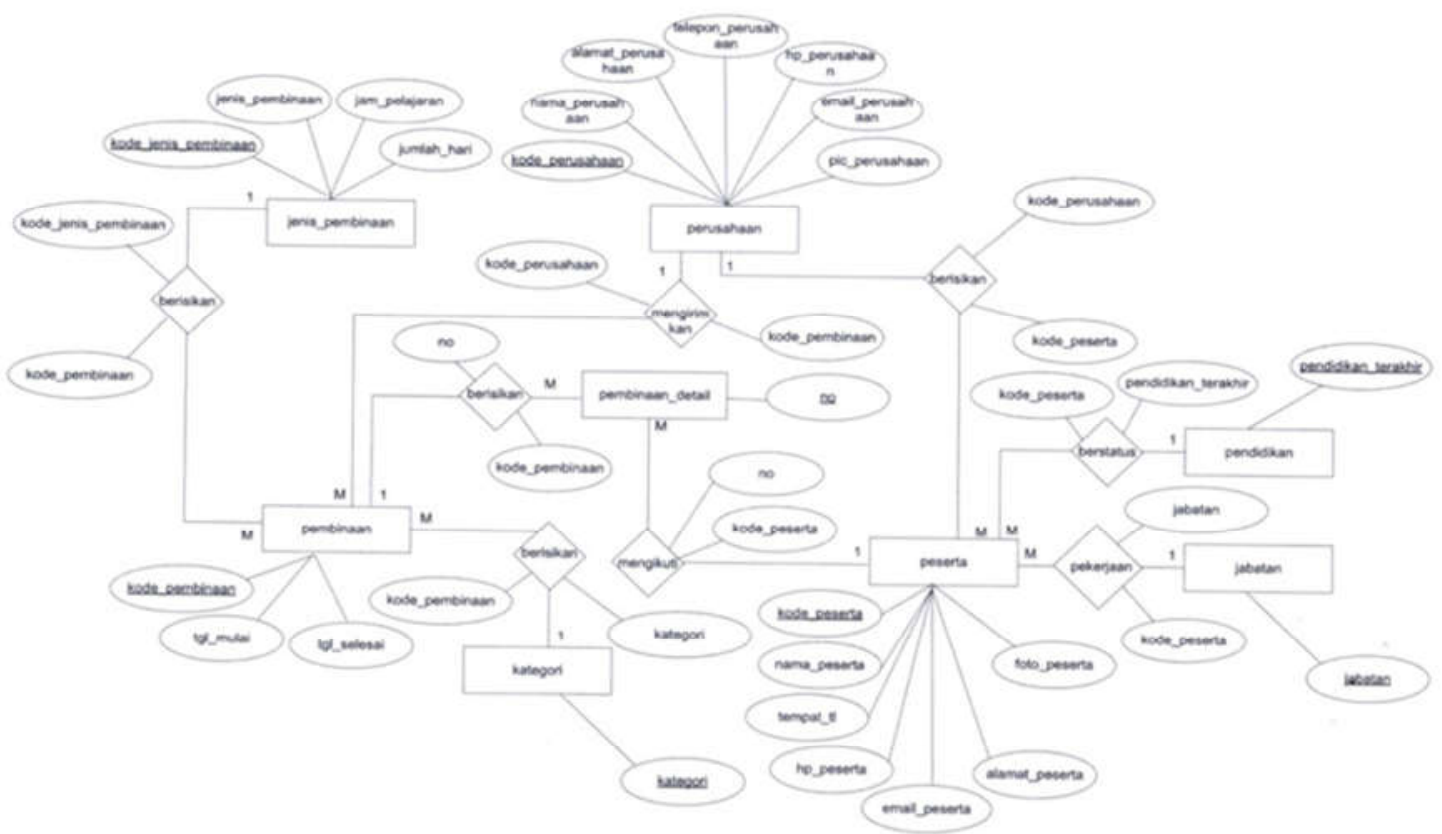

Gambar 8. Entity Relationship Diagram

\subsection{Rancangan Antar Muka Menu Utama}

\section{Menu Utama}

\begin{tabular}{|c|c|c|c|c|c|}
\hline File & Transaksi & Report & Utility & Exit & \\
\cline { 1 - 3 } Backup & $\begin{array}{c}\text { Input Data } \\
\text { Pembinaan }\end{array}$ & $\begin{array}{c}\text { Print Laporan } \\
\text { Pembinaan }\end{array}$ & \multicolumn{2}{|l}{} \\
\hline \hline
\end{tabular}

Gambar 9. Rancangan Antar Muka Menu Utama 


\section{KESIMPULAN}

Program administrasi pembinaan K3 pada PT. Exaudi Bina Karya Karawang sangat membantu dan mempermudah proses administrasi pembinaan $\mathrm{K} 3$, sehingga proses administrasi pembinaan K3 menjadi lebih baik dibandingkan dengan proses manual. Beberapa kelebihan yang didapatkan diantaranya:

1. Program administrasi pembinaan K3 mampu membuat proses input data menjadi lebih cepat, jika dibandingkan dengan proses manual. Selain itu tidak adanya redudansi data.

2. Tidak lagi memerlukan banyak dokumen fisik atau arsip penyimpanan, karena semua data telah disimpan dalam bentuk file.

3. Data laporan pembinaan K3 yang dihasilkan lebih akurat dan detail. Selain itu proses pencarian datanya juga lebih mudah dan lebih cepat.

\section{DAFTAR PUSTAKA}

Al Fatta, Hanif. 2007. Analisis dan Perancangan Sistem Informasi Untuk Keunggulan Bersaing Perusahaan dan Organisasi Modern. Yogyakarta: Andi.

Junindar. 2008. Panduan Lengkap Menjadi Programer Membuat Aplikasi Penjualan Menggunakan VB.Net. Jakarta Selatan: Mediakita

Kristanto, Andri. 2009. Algoritma dan Pemrograman dengan C++, Edisi 2. Yogyakarta: Graha Ilmu

Kusrini. 2007. Strategi Perancangan Pengelolaan Basis Data. Yogyakarta: Andi

Mangkulo, Hengky Alexander. 2010. Membangun Aplikasi Stok Inventori dengan

Nugroho, Adi. 2010. Rekayasa Perangkat Lunak Berorientasi Objek dengan Metode USDP (Unified Software Development Process). Yogyakarta: Andi.

Riyanto. 2005. Migrasi Microsoft SQL Server dengan PostgreSQL. Jakarta: Elex Media Komputindo.

Sadeli, Muhammad. 2009. 7 Jam Belajar Interaktif Visual Basic.net 2008. Palembang: Maxikom.

Sadeli, Muhammad. 2012. Pemrograman Database dengan Visual Basic 2010 untuk Orang Awam. Palembang: Maxikom.

Sarosa, Samiaji. 2009. Sistem Informasi Akuntasi. Jakarta: Grasindo.

Sutarman. 2009. Pengantar Teknologi Informasi. Jakarta: Bumi Aksara

Rosa dan M. Shalahuddin. 2015. Rekayasa Perangkat Lunak Terstruktur Dan Berorientasi Objek. Bandung: Informatika 